\title{
Improving the effects of pedometer use in individuals 65 years of age and older, under the supervision of family physician
}

\begin{abstract}
Objective: Pedometer use in elderly patients, and assessing the possible potentiation of the effects of pedometer use by close follow-up of the patient. The aim of this study was to assess changes in physical activity among elderly individuals based on pedometer readings and motivational interviews

Methods: The study was conducted with individuals 65 years of age and older. Group 1 (pedometer+interview group) comprised 41 individuals, and group 2 (pedometer only group), 36 individuals. The participants' anthropometric measurements, counts of GDS and steps were compared.

Results: Final GDS was significantly lower in group 1 than in group $2(p<0.001)$. At the end of the 12-month study, the BMI values were lower than at baseline $(28.19 \pm 2.89$ vs. $28.73 \pm 14.94 \mathrm{~kg} / \mathrm{m} 2 ; \mathrm{p}<0.001)$ in group 1 and higher in group $2(27.77 \pm 2.72$ vs. $27.69 \pm 2.77 \mathrm{~kg} / \mathrm{m} 2 ; \mathrm{p}=0.033)$. The WHR change was higher in group 1 than in group 2 $(0.02 \pm 0.04$ vs. $0 \pm 0.04 \mathrm{~cm}$; z:-5.051, p<0.001).

Conclusion: This represents the first study to our country in primary care .Regular walking should be part of daily life in people of all ages, but especially in elderly individuals to prevent negative effects that can occur with increasing age. Primary care physicians can play an important role in encouraging regular free walking by their patients by emphasizing its protective and remedial effects
\end{abstract}

Keywords: family physician, older adults, pedometer, primary health care, regular control
Volume I Issue 2 - 2017

\author{
Sebahat Gucuk,' Neslihan Erkuran² \\ 'Department of Family Medicine, Abant Izzet Baysal University, \\ Turkey \\ ${ }^{2}$ Golyuzu Family Health Center,Turkey
}

\begin{abstract}
Correspondence: Sebahat Gücük, Department of Family Medicine, Abant Izzet Baysal University, Bolu,Turkey, Tel+ 05056748192, Email sebahatgu@yahoo.com
\end{abstract}

Received: March 08, 2017 | Published: April 05, 2017
Abbrevations: BMI, body mass index; WHR, waist/hip ratio; GDS, geriatric depression scale

\section{Introduction}

According to the World Health Organization, old age entails a gradual decrease in the ability to adjust to environmental factors, with individuals aged 65 years and older defined as old. The sociological, biological, and psychological decline is accompanied by changes in functional capacity induced by decreased cardiovascular, respiratory, and metabolic functioning. ${ }^{1,2}$ Physical activity is beneficial for health and well-being in old age. However, physical activity has been shown to decrease as adults become older. ${ }^{3}$ During old age, there may also be changes in social, economic, and health status as well as in family structure. The loss of a spouse or close friends or relatives can lead to loneliness, an inability to cope with daily life; and a decrease in social support, which together can result in depression. ${ }^{4}$ An alternative approach that has yielded highly positive results in the management of depression in elderly individuals is exercise. ${ }^{5}$ Regular exercise provides benefits to the elderly not only in terms of eliminating the depressive mood, but also in terms of several other aspects. Some of the guidelines prepared in compliance with the WHO's suggestions recommend that individuals aged 65 and older should do medium density physical activities for a total of 300 minutes per week or similar physical activities in various durations and densities in order for the physical activity to be sufficiently beneficial for health. ${ }^{6}$ Nonetheless, many older individuals hesitate to exercise because they fear the risk of injury; however, this is not the case with walking. ${ }^{7}$
Simple and affordable pedometers are generally considered practical for individual- and population-based applications, as they provide a summary of the daily number of steps. ${ }^{8}$ Although pedometers are widely used in many countries to measure physical activity, their use in Turkey is very limited. However, the Republic of Turkey Ministry of Health, with the support of the country's primary care healthcare professionals, has been conducting several projects aimed at encouraging exercise and greater physical activity in individuals of all ages.

The aim of this study was to assess changes in physical activity among elderly individuals based on pedometer readings and motivational interviews. The primary outcome measures were weight change, body mass index (BMI), and waist/hip ratio (WHR). As a secondary outcome measure, scores on the Geriatric Depression Scale (GDS) were determined.

\section{Methods}

Our randomized controlled study was conducted in patients 65 years of age and older who were registered at the Bolu Izzet Baysal Family Health Center (Turkey)) between April 2014 and March 2015. Of the 395 registered patients over 65 years of age were contacted by telephone and invited to participate in the study, resulting in 130 participants. Based on the order of their enrollment, they were randomized into two groups. A total of 77 of these participants, who were randomized in 2 groups according to the order of registration, were able to complete the study (Figure 1). 


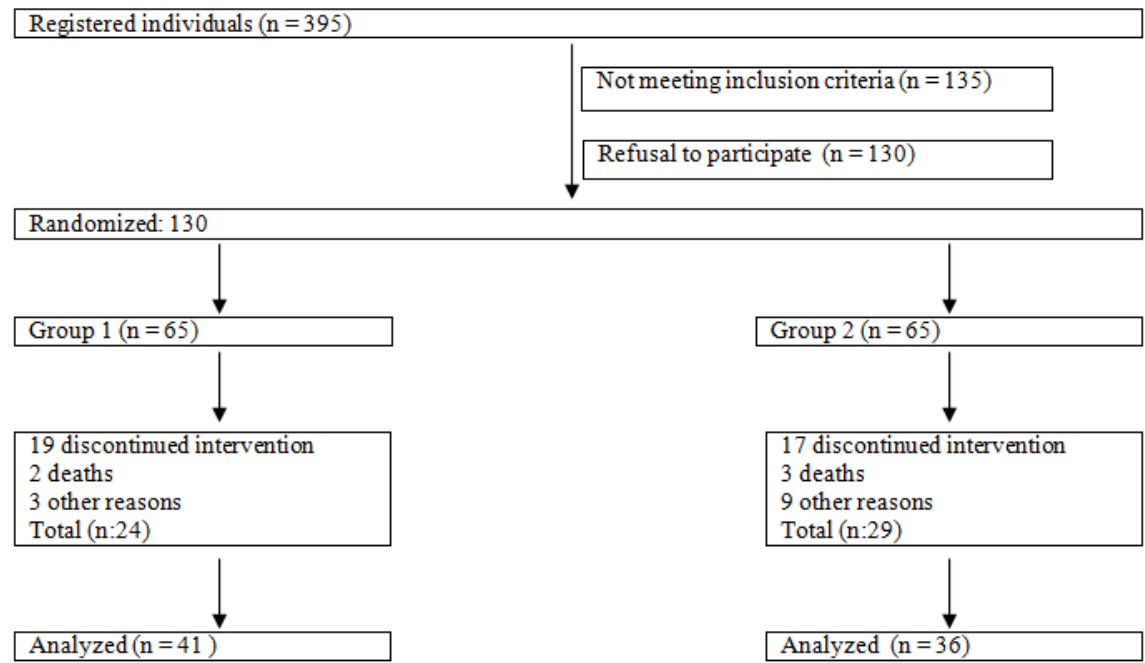

Figure I Recruitment flowchart and identification of the eligible population.

The participants were first asked to complete a questionnaire about socio-demographic characteristics, a mini mental-status exam ${ }^{9}$ and a short physical performance battery ${ }^{10}$ to evaluate physical function. All participants were administered a geriatric depression scale of 30 questions (GDS-30). ${ }^{11}$ Patients receiving depression-related psychiatric treatment or who, in our opinion, should receive such treatment, patients scoring $<23$ points on the mini mental-status exam, those whose static balance (eyes open and closed) was suboptimal, and those not willing to participate were excluded from the study. Patient height and weight was measured. BMI was calculated as weight (kg)/ height (m2)). WHR was measured in $\mathrm{cm}$ based on the waist and hip circumference, determined using a tape measure. ${ }^{12}$

Initially, each participant was given nutrition and exercise training, together with a 7-day retroactive TNV $3 \mathrm{~d} \AA$ pedometer. The pedometers were supplied at no cost to the patients, in accordance with the Ministry of Health's instructions. During the 12-month monitoring period, the patients were asked to keep the pedometers on a belt over one hip 7 days/week, except when showering or bathing. As in the Hernandez et al. study, both groups were checked up on every 2 months in the clinic or during house visits. ${ }^{13}$ From their pedometers, the recorded average data, the GDS scores, the weight BMI, and the WHY values of the latest week were calculated. In addition, bi-weekly telephone interviews were conducted with participants in the pedometer + interview group (Group 1), where patients were asked about their current exercise status. During the interview, the most recent number of steps was evaluated and discussed with the patient, without any time constraints, and advice was given regarding potential sources of confusion or improvement. For the patients in the pedometer only group (group 2), only their pedometer and other measurements were taken, while they were not provided with this additional motivation.

\section{Ethics}

Our study was conducted using volunteers as participants, and permission was received from our local health authority.

\section{Statistical analyses}

The data were analyzed using SPSS version 20 for Windows (SPSS, Chicago IL, USA). For variables with normal distribution, the
Shapiro-Wilks test was applied. For variables that were not normally distributed, differences between groups were determined using the Mann-Whitney U- and Kruskal-Wallis H-tests. Because the $\mathrm{n}$ values were $>20$, standardized $z$ values were used for the Mann-Whitney U-test. Significant differences identified with the Kruskal-Wallis $\mathrm{H}$-test were further analyzed using a post hoc multiple comparison test. The relationships between groups in categorical variables were assessed using a $\chi^{2}$ test. When the values expected in the cells of the $2 \times 2$ tables were too small, Fisher's exact test was applied. For the $\mathrm{R} \times \mathrm{C}$ tables, a Pearson $\chi^{2}$ analysis was applied using a Monte Carlo simulation. A p-value $<0.05$ was considered to indicate statistical significance.

\section{Results}

Some characteristics of both groups in the initial stages of the study were shown in (Table 1). The average age of the group 1 patients was $72.44 \pm 5.41$ years, and that of the group 2 patients $74.28 \pm 4.79$ years. None of the participants was actively employed. In groups 1 and $2,65.85 \%(\mathrm{n}=27)$, and $71.43 \%(\mathrm{n}=28)$, respectively, had been previously employed but were retired at the time of the study. There was no difference between groups with respect to sex, education level, marital status, domestic status, residence, and physical exercise frequency $(\mathrm{p}>0.05)$.

The initial average GDS score was not significantly between two groups ( $p=0.121)$. But the final score was significantly lower in group 1 than in group $2(p<0.001)$. The GDS in group 2 was higher at the end of the study than at baseline $p<0.001$ ). In parallel with the increase in the average number of steps recorded at the bimonthly measurements, the average GDS decreased. In the post hoc analysis, although this relation was not a strong one at the final interview, the correlation was confirmed as negative $(\mathrm{r}:-0.248, \mathrm{p}=0.038)$.

Average weight loss in group $1(1.14 \pm 1.35 \mathrm{~kg})$ was less (z:-4.601; $\mathrm{p}=0.001)$ than that in group $2(2.2 \pm 10.9 \mathrm{~kg})$, but at the end of 12 months, when current weights within groups were compared with their initial weights, there was a meaningful weight loss in the $1^{\text {st }}$ Group. $\mathrm{p}<0.001)$ At the end of the 12-month study, the BMI values were lower than at baseline $\left(28.19 \pm 2.89\right.$ vs. $\left.28.73 \pm 14.94 \mathrm{~kg} / \mathrm{m}^{2} ; \mathrm{p}<0.001\right)$ in group 1 and higher in group $2\left(27.77 \pm 2.72\right.$ vs. $27.692 .77 \mathrm{~kg} / \mathrm{m}^{2}$; 
$\mathrm{p}=0.033)$. The WHR change was higher in group 1 than in group 2 $(0.02 \pm 0.04$ vs. $0 \pm 0.04 \mathrm{~cm}$; z:-5.051, p<0.001). Furthermore, WHR in group 1 patients decreased between the beginning and end of the study $(\mathrm{p}<0.001)$, whereas that in group 2 increased $(\mathrm{p}=0.009)$.

The average number of steps taken was higher at all time points in group 1 than in group 2, as was the average number steps at the end of 12 months (5476 \pm 1359.14 steps/day) compared to the baseline value
(4464 725.43 steps/day; $\mathrm{p}<0.001$ ). The change in the number of steps/ day over the 12-month period was $1011.15 \pm 834.81$ in group 1 and $990.37 \pm 825.11$ in group $2(\mathrm{z}:-0.015 ; \mathrm{p}=0.988)$ (Table 2) Even though the difference between the final and initial values of the groups were meaningful, when the two groups were compared with each other, no difference was observed with regards to the average number of steps. (p:0.764).

Table I Baseline characteristics of the participants

\begin{tabular}{|c|c|c|c|c|}
\hline \multirow{2}{*}{$\begin{array}{l}\text { Characteristics } \\
\text { Sex }\end{array}$} & \multicolumn{2}{|c|}{ Group I $(n=4 I)$} & \multirow{2}{*}{$\begin{array}{l}\text { Group } 2(n=36) \\
19(52.78 \%)\end{array}$} & \multirow{2}{*}{$\begin{array}{l}\text { P-value } \\
0.938\end{array}$} \\
\hline & Female & $22(53.66 \%)$ & & \\
\hline & Male & 19 (46.34\%) & $17(47.22 \%)$ & \\
\hline \multirow[t]{3}{*}{ Marital status } & Married & $25(61 \%)$ & $19(52.8 \%)$ & 0.712 \\
\hline & Widowed & 14 (34.1\%) & 14 (38.9\%) & \\
\hline & Divorced & $2(4.9 \%)$ & $3(8.3 \%)$ & \\
\hline \multirow[t]{5}{*}{ Domestic status } & Alone & $4(9.8 \%)$ & $3(8.3 \%)$ & 0.121 \\
\hline & With spouse & $16(39 \%)$ & $13(36.1 \%)$ & \\
\hline & With spouse and children & $16(39 \%)$ & $7(19.4 \%)$ & \\
\hline & & $4(9.8 \%)$ & II (30.6\%) & \\
\hline & Other & I (2.4\%) & $2(5.6 \%)$ & \\
\hline Any diagnosed chronic & Yes & $38(92.7 \%)$ & $29(80.6 \%)$ & 0.175 \\
\hline disease & No & $3(7.3 \%)$ & $7(19.4 \%)$ & \\
\hline \multirow[t]{2}{*}{ Residence } & House & 19 (46.34\%) & $19(52.78$ & 0.573 \\
\hline & Condo & $22(53.66 \%)$ & $17(47.22 \%)$ & \\
\hline \multirow[t]{3}{*}{ Frequency of physical exercise } & None & $24(\% 58,5)$ & $13(36,1)$ & 0.134 \\
\hline & $\mathrm{I}-2$ times a week & $14(34,1)$ & $17(47,2)$ & \\
\hline & 3 or more times a week & $3(\% 7,3)$ & $6(16,7)$ & \\
\hline
\end{tabular}

Table 2 Post-study changes among groups

\begin{tabular}{|c|c|c|c|c|c|}
\hline & & Group I $n=4$ I (mean \pm SD $\%)$ & Group 2 n=36 (mean \pm SD $\%)$ & $\mathbf{z}$ & $\mathbf{p}$ \\
\hline \multirow[t]{2}{*}{ GDS total } & Beginning & $8.9 \pm 3.12$ & $9.83 \pm 2.44$ & -1.552 & 0.121 \\
\hline & 12 months & $7.73 \pm 2.17$ & $10.72 \pm 2.99$ & -4.25 & 0.001 \\
\hline \multirow[t]{3}{*}{ Weight (kg) } & Beginning & $76.23 \pm 8.9$ & $74.67 \pm 7.41$ & -0.297 & 0.767 \\
\hline & 12 months & $75.09 \pm 8.22$ & $72.47 \pm 12.36$ & -0.179 & 0.858 \\
\hline & Beginning & $28.73 \pm 3.2$ & $27.69 \pm 2.77$ & -1.389 & 0.165 \\
\hline BMI (kg/m2) & 12 months & $28.19 \pm 2.89$ & $27.77 \pm 2.72$ & -0.633 & 0.527 \\
\hline \multirow[t]{2}{*}{ Waist/hip ratio } & Beginning & $0.99 \pm 0.17$ & $0.92 \pm 0.1$ & -1.737 & 0.082 \\
\hline & $\begin{array}{l}12 \text { months } \\
\text { months }\end{array}$ & $0.97 \pm 0.16$ & $0.93 \pm 0.08$ & -0.684 & 0.494 \\
\hline $\begin{array}{l}\text { Baseline pedometer readings over } \\
7 \text { days: mean number of steps }\end{array}$ & Beginning & $4464.93 \pm 725.43$ & $4390.28 \pm 684.26$ & -0.546 & 0.585 \\
\hline number of steps $\mathrm{s}^{\mathrm{a}}$ & 12 months & $5476.08 \pm 1359.14$ & $5380.65 \pm 1317.65$ & -0.3 & 0.764 \\
\hline
\end{tabular}

$*_{p}<0.05$

aMean number of steps $=$ total number of steps recorded by the pedometer divided by the number of days

GDS, geriatric depression score; BM

Citation: Gucuk S, Erkuran N. Improving the effects of pedometer use in individuals 65 years of age and older, under the supervision of family physician. MOJ Gerontol Ger. 2017; I (2):48-52. DOI: I0.15406/mojgg.2017.01.000I I 


\section{Discussion}

Regular walking plays an important role in increasing the activity level of sedentary people and therefore in improving the health of society. It is a simple form of exercise that can be performed by individuals of all ages and socio-economic groups, and by women as well as men. Moreover, walking is a life-long form of exercise that can maintain general health over the long term. In fact, it is the most frequently prescribed non-pharmacologic treatment in the world. ${ }^{14}$

To measure physical activity independent of patients' subjective self-report, pedometers have been introduced into clinical studies. Their advantages include their small size, relatively low cost, ${ }^{15,16}$ and the positive feedback they provide with respect to the daily numbers of steps taken. ${ }^{17}$ Therefore, we decided to measure the level of physical exercise of our elderly patients via pedometers. Furthermore, we tried to find out whether their physical activities could be improved by conducting close follow-ups and motivating them through interviews.

Randomized studies and meta-analyses have confirmed the antidepressant affect of physical activity and exercise in older adults with clinical depression. ${ }^{18}$ Physical activity was also shown to have long-term effects in improving mood ${ }^{19}$ and in reducing depressive symptoms.$^{20}$ Moderate aerobic activity, such as walking, ${ }^{21}$ has positive effects, as does progressive resistance training. Furthermore, these positive effects result in an increase in the frequency of the respective activities and increase with longer duration of the intervention. ${ }^{22}$ In our study, the GDS values of the participants in the 1st Group were significantly better than the other group. Furthermore, a correlation was found between the increased number of steps and the decreased GDS scores according to the assessment that was conducted every 2 months with this group. However, even though the number of steps showed an increase in the 2nd group, there was no decrease in their GDS scores. Therefore, it is plausible to think that a decrease in the GDS scores in the 1st group can be explained not only with the increase in number of steps, but also with the possible effects of phone calls conducted every 2 weeks with this group, along with the suggestions made, and the attention shown.

Excessive visceral fat and central obesity are related to several cardiovascular diseases and to mortality. ${ }^{23}$ The WHR, a measure of relative fat distribution, has been used to determine health risks. ${ }^{24}$ Duchečková reported high WHR values in individuals with a low level of physical activity. ${ }^{25}$ In a population-based study, the number of steps taken was shown to be inversely related to low BMI and low WHR. Similarly, another study found that the number of steps/ day was inversely related to abdominal obesity. ${ }^{26}$ Our results are in agreement with those of other studies. Considering our study from these points of view, there was no difference between the two groups regarding loss of weight and the changes in the BMI values, while the groups were significantly better than their initial values. In terms of WHR, while there was a meaningful decrease in the 1st Group compared to the $2 \mathrm{nd}$, an increase in the WHR was observed in the $2^{\text {nd }}$ Group. Considering the fact that all these values are significant in terms of fat distribution and the general cardiovascular health, it can be said that physical activity with a pedometer is beneficial. However, it is also true that the interviews conducted with the 1st Group had a minimal effect on these values.

It was stated that regardless of the well-known benefits of physical activities, especially the $45 \%$ of the population over 65 of age do not meet the recommended levels of physical activity. This is a rapidly increasing problem as the number of people aged over 65years in the world is expected to triple in the next 30 years. 300 minutes of medium density aerobic physical activity per week is recommended for the elderly in order to bring out adequate benefits of exercising. ${ }^{6}$ In their study of older adults, Rowe et al. recommended an average of $7000-8000$ steps/day. ${ }^{27}$ In Turkey, where primary care health services are steadily improving, the Ministry of Health has developed several motivational programs aimed at elderly people but appropriate for every age group. In our study, the participants' average number of steps were between 5000 and 6000 . Following the introduction of a pedometer, by the end of the study, the number of steps increased in participants; the increase from the initial values was significant in group 1 as well as group 2. Thus, our results show that the support provided simply by giving patients a pedometer and contacting them via regular interviews leads to an increase in the number of steps taken. The absence of a significant difference in the number of steps taken by groups 1 and 2 independent of the training provided might have reflected a limit for increasing the number of steps in this relatively inactive age group. However, this also demonstrates the importance and motivational effect of encouragement by health professionals.

\section{Limitations}

The results of the present study may also be applicable to the Turkish population. However, a limitation of our study was the small number of patients representing a single geographic area. Also, our patients had no serious mobility problems, and had good cognitive function and adequate verbal communication. Furthermore, their physical activities were monitored only in terms of the number of steps, and their walking speed was not standardized. Our study will encourage other studies with a longer duration of monitoring and wider participation, in addition to raising awareness of the positive effects of walking in elderly individuals.

\section{Conclusion}

Regular walking should be part of one's life style during every period of life, but it is especially important in preventing the negative effects that typically occur with increasing age. In Turkey, health policies are currently being developed to encourage physical exercise. As primary care physicians, we should recommend regular free walking to our patients, given its protective and remedial effects, and encourage all members of the population to walk regularly.

\section{Disclosure statement}

This study did not receive any specific funding or grants. The authors have no conflicts of interest to declare.

\section{Acknowledgements}

None.

\section{Conflict of interest}

Author declares there is no conflict of interest in publishing the article.

\section{References}

1. Ergun GO, Bozdemir N, Uguz S, et al. Evaluation of the medical and social characteristics of theelderly living at the community residence of Adana and those applying to the family medicine outpatient clinic. Turkish Journal of Geriatrics. 2003;6(3):89-94. 
2. Bryg RJ, Williams GA, Labovitz AJ. Effect of aging on left ventricular diastolic filling in normal subjects. Am J Cardiol. 1987;59(9):971-974.

3. Barnett I, Guell C, Ogilvie D. The experience of physical activity and the transition to retirement: a systematic review and integrative synthesis of qualitative and quantitative evidence. International Journal of Behavioral Nutrition and Physical Activity. 2012;8(16):9-97.

4. Prince MJ, Harwood RH, Thomas A, et al. A prospective populationbased cohort study of the effects of disablement and social milieu on the onset and maintenance of late-life depression. Psychol Med 1998;28(2):337-350.

5. Lawlor DA, Hopker SW. The effectiveness of exercise as an intervention in the management of depression: Systematic review and meta-regression analysis of randomised controlled trials. BMJ. 2001;322(7289):763-767.

6. Franco MR, Tong A, Howard K, et al. Older people's perspectives on participation in physical activity: a systematic review and thematic synthesis of qualitative literature. Br J Sports Med. 2015;49(19):1268-76.

7. Murphy M, Nevill A, Neville C, et al. Accumulating brisk walking for fitness, cardiovascular risk, and psychological health. Med Sci Sports Exerc. 2002;34(9):1468-74.

8. Tudor-Locke C, Ham SA. Walking behaviors reported in the American time use survey 2003-2005. J Phys Act Health. 2008;5(5):633-647.

9. Folstein, MF, Folstein SE, McHugh PR. Mini-Mental State: A practical method for grading the cognitive state of patients for the clinician. $J$ Psychiatr Res. 1975;12(3):189-198.

10. Fisher S, Ottenbacher KJ, Goodwin JS, et al. Short physical performance battery in hospitalized older adults. Aging Clinical and Experimental Research. 2009;21(6):445-52.

11. Yesavage JA, Brink TL, Rose TL, et al. Development and validation of a geriatric depression screening scale: a preliminary report. J Psychiatr Res. 1982-1983;17(1):37-49.

12. Sardinha LB, Teixeira PJ, Guedes DP, et al. Sub cutaneous central fat is associated with cardiovascular risk factors in men independently of total fatness and fitness. Metabolism. 2009;49(11):1379-1385.

13. Hernandez R, Prohaska TR, Wang PC, et al. The longitudinal relations hip between depression and walking behavior in olderLatinos: The “¿Caminemos!” study. J Aging Health. 2013;25(2):319-341.

14. Cox KL, Burke V, Gorely T J, et al. Controlled comparison of adherence in home- vs. center-initiated exercise interventions in women ages 45-65 years. Prev Med. 2003;36(1):17-29.
15. Strasser B. Physical activity in obesity and metabolic syndrome. Ann N Y Acad Sci. 2013;1281(1):141-159.

16. Cayir Y, Aslan SM, Akturk Z. The effect of pedometer use on physical activity and body weight in obese women. Eur J Sport Sci. 2015;15(4):351-356.

17. Sung-Hyoun Cho, Byoung-Don Oh, Byung-Jun Cho. Analysis according to gender and body mass index of the number of steps taken by sedentary workers as measured by a pedometer. $J$ Phys Ther Sci. 2013;25(8):919-921.

18. James A Blumenthal, Michael A Babyak, Kathleen A Moore, et al. Effects of exercise training on older patients with major depression. Arch Int Med. 1999;159(19):2349-2356.

19. Singh NA, Clements KM, Fiatarone MA. A randomized controlled tria of progressive resistance training in depressed elders. $J$ Gerontol $A$ BiolSci Med Sci. 1997;52(1):27-35.

20. Dunn AL, Trivedi MH, O’Neal HA. Physical activity dose-response effects on outcomes of depression and anxiety. Med Sci Sports Exerc. 2001;33(6):S587-597.

21. McNeil JK, LeBlanc EM, Joyner M. The effect of exercise on depressive symptoms in the moderately depressed elderly. Psychol Aging. 1991;6(3):487-88

22. Brosse AL, Sheets ES, Lett HS, et al. Exercise and the treatment of clinical depression in adults: recent findings and future directions. Sports Med. 2002;32(12):741-760.

23. Ibrahim MM. Subcutaneous and visceral adipose tissue: structural and functional differences. Obes Rev. 2010;11(1):11-18.

24. Welborn TA, Dhaliwal SS, Bennett SA. Waist-hipratio is the dominant risk factor predicting cardiovascular death in Australia. Med J Aust. 2003;179(11-12):580-585.

25. Duchečková $\mathrm{P}$, Forejt M.Aerobic steps as measured by pedometry and their relation to central obesity. Iran J Public Health. 2014;43(8):1070-1078.

26. Jennersjö P, Ludvigsson J, Länne T, et al. Pedometer-determined physical activity is linked to low systemic inflammation and low arterial stiffness in Type 2 diabetes. DiabetMed. 2012;29(9):1119-1125.

27. Rowe DA, Kemble CD, Robinson TS, et al. Daily walking in older adults: day-to-day variability and criterion-referenced validity of total daily step counts. J Phys Act Health. 2007;4(4):434-446. 